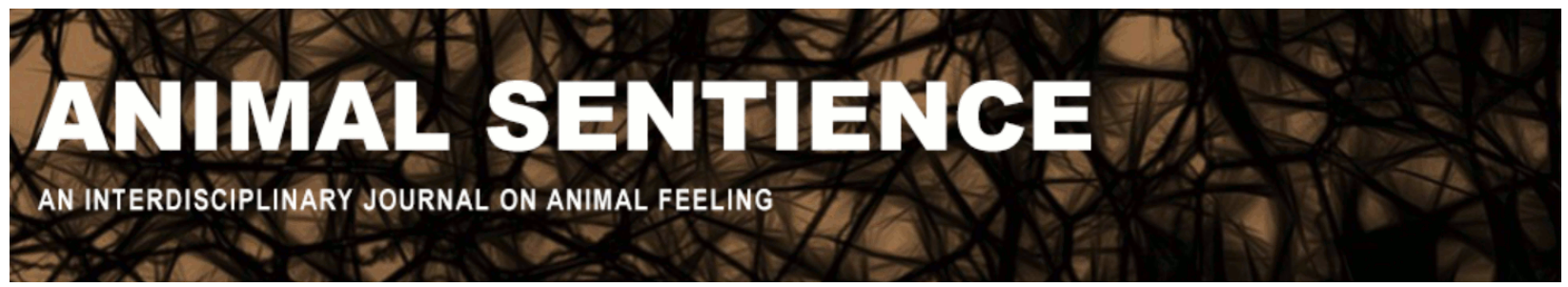

Teichroeb, Julie A. (2017) Methodological suggestions for inferring fear from vigilance. Animal Sentience 15(6)

DOI: $10.51291 / 2377-7478.1293$

Date of submission: 2018-01-08

Date of acceptance: 2018-01-11

(c) (†)

This article has appeared in the journal Animal

Sentience, a peer-reviewed journal on animal

cognition and feeling. It has been made open access,

free for all, by WellBeing International and deposited

in the WBI Studies Repository. For more information,

please contact

wbisr-info@wellbeingintl.org.

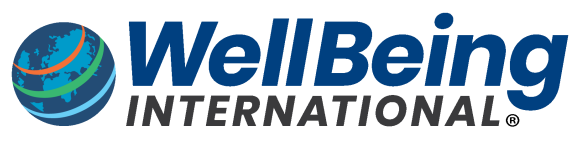

SOLUTIONS FOR PEOPLE, ANIMALS AND ENVIRONMENT 


\title{
Methodological suggestions for inferring fear from vigilance
}

Commentary on Beauchamp on Fear \& Vigilance

\author{
Julie A. Teichroeb \\ University of Toronto Scarborough
}

\begin{abstract}
I suggest some methods for data-collection and analysis that may help researchers infer fear from vigilance.
\end{abstract}

Julie A. Teichroeb is a primate behavioural ecologist at the University of Toronto studying the cost and benefits of groupliving to different individuals in social groups, with the goal of understanding the underlying causes of social organization. www.julieteichroeb.com

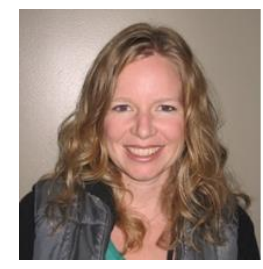

Plutchik (1997) cites eight basic emotions - fear, anger, sadness, joy, disgust, surprise, trust, and anticipation - but an inventory of emotional states is not typically addressed by behavioural ecologists. Fear is a notable exception, as Beauchamp (2017) points out in his target article. Many studies assume there is fear whenever animals are vigilant. Why are we confident that animals experience fear in these situations yet are hesitant to accept evidence for other emotional states? Is it because fear seems more basic or primal than other emotions? Beauchamp shows that the evidence for a strong link between vigilance and fear is tenuous, because vigilant animals may not show any physiological correlates of fear and animals may be fearful without showing overt signs of vigilance. One factor in this decoupling of vigilance and fear is that animals may be monitoring aspects of the environment that do not make them fearful, such as food, mates, or social partners (e.g., Caine \& Marra, 1988; Hirsch, 2002; Makowska \& Kramer, 2007).

As with other emotions, it is important to be cautious in attributing fear to our study animals. We will never know for sure. It is usually too costly and time-intensive to monitor the physiological correlates of fear (e.g., heartrate, stress hormones, pupil dilation) in wild animals. Since vigilance is strongly affected by the presence of a predator (e.g., Hunter \& Skinner, 1998) and is cheaply and easily monitored, it could provide a strong correlate of fear if the proper controls are used in data collection and analysis. In the last page of his target article, Beauchamp cites a few methods that could be used to tighten the association between vigilance and fear. Here, I provide a few more ways researchers could strengthen the inference that an animal is experiencing fear.

Recording as much information as possible about the situation and the act of vigilance, may help identify when vigilance is directed at frightening stimuli in later analysis. The researcher can often discern whether the target is threatening to the focal animal. A predator represents an obvious threat, but researchers who know individual animals and understand the social situation may also discern social threats. During challenges to the existing dominance hierarchy, for example, new males entering the social group, infanticidal attacks, a high-ranking individual 
approaching a low-ranking individual with a certain posture/signal, etcetera, may all provide information. Beauchamp makes the excellent point that determining the target of vigilance is far easier for animals with forward-facing eyes, although for animals with lateral eyes, vigilance directed towards predators can sometimes still be discerned if the researcher relies on other external cues to predator presence (e.g., alarm calls, recent attacks, locus in home range).

Recording the intensity of the vigilance can also be useful. Blanchard and Fritz (2007) refer to a difference between routine and induced vigilance. Animals may monitor their environment whenever they have spare time (routine vigilance), but when vigilance is evoked by a stimulus, they interrupt their feeding or other activity to look in a particular direction (induced vigilance); this is a costlier behaviour. Induced vigilance is more likely than routine scanning to be associated with fear. It can be helpful to record and compare vigilance behaviour at two different intensities, defined by the speed with which the head is raised or turned and the length of time that the animal looks in a particular direction (Teichroeb \& Sicotte, 2012).

Routine vigilance may also be directed at monitoring the food supply, so it should be excluded from analyses when one is interested in the link between vigilance and fear. Another way to filter out food scanning is to analyze only the data for when animals are resting rather than feeding. Feeding animals should not be compared with resting animals (Bednekoff, 2003; Teichroeb \& Sicotte, 2012). Beauchamp also suggests excluding factors that may interfere with a link between fear and vigilance, such as hunger or a lack of habituation to human observers.

To sum up, relatively simple methods applied at the data collection and analyses stages, such as recording the target of vigilance, controlling for the situation and recent events, and recording the intensity of vigilance can help strengthen a researcher's case for inferring fear. Unfortunately, however, as with other emotions, one can never know for sure what any animal is feeling (Andrews, 2014).

\section{References}

Andrews, K. (2014). The animal mind: An introduction to the philosophy of animal cognition. Routledge. Beauchamp, G. (2017). What can vigilance tell us about fear? Animal Sentience, 15(1).

Bednekoff, P. A. (2003). Testing explanations of the group size effect on vigilance: let's be direct. Behavioural Processes, 63, 135-136.

Blanchard, P., \& Fritz, H. (2007). Induced or routine vigilance while foraging. Oikos, 116, 1603-1608.

Caine, N. G., \& Marra, S. L. (1988). Vigilance and social organization in two species of primates. Animal Behaviour, 36, 897-904.

Hirsch, B. T. (2002). Social monitoring and vigilance behavior in brown capuchin monkeys (Cebus apella). Behavioral Ecology and Sociobiology, 52, 458-464.

Hunter, L. T. B., \& Skinner, J. D. (1998). Vigilance behaviour in African ungulates: the role of predation pressure. Behaviour, 135, 195-211.

Makowska, I. J., \& Kramer, D. L. (2007). Vigilance during food handling in grey squirrels, Sciurus carolinensis. Animal Behaviour, 74, 153-158.

Plutchik, R. (1997). The circumplex as a general model of the structure of emotions and personality. In R. Plutchik \& H. R. Conte (Eds.), Circumplex Models of Personality and Emotions (pp. 17-45). Washington, DC: American Psychological Association.

Teichroeb, J. A., \& Sicotte, P. (2012). Cost-free vigilance during feeding in folivorous primates? Examining the effect of predation risk, scramble competition, and infanticide threat on vigilance in ursine colobus monkeys (Colobus vellerosus). Behavioral Ecology and Sociobiology, 66, 453-466. 